\title{
MAPEAMENTO DAS PASTAGENS NO MUNICÍPIO DE UBERLÂNDIA EM 2015
}

\author{
Jorge Luis Silva Brito $^{(\mathrm{a})}$, Jéssica Palomares Leal ${ }^{(\mathrm{b})}$
}

(a) Insituto de Geografia - Universidade Federal de Uberlândia, jbrito@ufu.br

(b) Insituto de Ciências Agrárias - Universidade Federal de Uberlândia, jessica_pleal@ hotmail.com

Eixo: Uso e ocupação das terras e legislação ambiental

\begin{abstract}
Resumo
O presente trabalho teve como objetivo mapear as áreas de pastagens plantadas, estimar a porcentagem de cobertura verde e de produtividade de biomassa verde dessas pastagens no município de Uberlândia. Para o mapeamento foram utilizadas imagens do Sensor OLI do satélite Landsat-8. Os valores de porcentagem de cobertura verde e biomassa verde foram estimados a partir do índice de vegetação EVI2. Os resultados mostraram que as áreas de pastagens ocupam uma área $1324,85 \mathrm{Km}^{2}$, correspondendo a 32,19\% da área do município de Uberlândia. As áreas de baixa produtividade de Biomassa Verde, entre 500 e $1500 \mathrm{~kg} / \mathrm{Ha}$, e baixa porcentagem de Cobertura Verde, menor que 40\%, estão concentrados na porção sudoeste do município, onde os solos são mais arenosos, enquanto as áreas de alta produtividade de Biomassa Verde, maiores que $2500 \mathrm{Kg} / \mathrm{Ha}$ estão localizados na porção norte do município, onde ocorrem solos mais argilosos.
\end{abstract}

Palavras chave: Mapeamento; Índice de vegetação; Pastagem; Biomassa; Uso da terra.

\section{Introdução}

O uso indiscriminado das áreas de pastagens com elevada carga animal e a falta de correção e fertilização dos solos impôs um processo de extrativismo, pela exportação do produto animal, condicionado à perda da capacidade produtiva das pastagens.

A degradação de pastagens é entendida como um processo evolutivo de perda de vigor, produtividade, e capacidade de recuperação natural, tornando-as susceptíveis aos efeitos nocivos de pragas, doenças e plantas invasoras, culminando com a degradação avançada dos recursos naturais em razão de manejos inadequados (MACEDO e ZIMMER, 1993).

Estudos tem demonstrado o potencial do uso de imagens de satélite associadas aos índices de vegetação para a caracterização, discriminação e estudo da porcentagem de cobertura verde e biomassa de pastagens cultivadas no bioma Cerrado (FERREIRA ET al., 2012; SANO ET al., 2002; ANJOS et al., 2013; FRANCO e ROSA, 2004). 


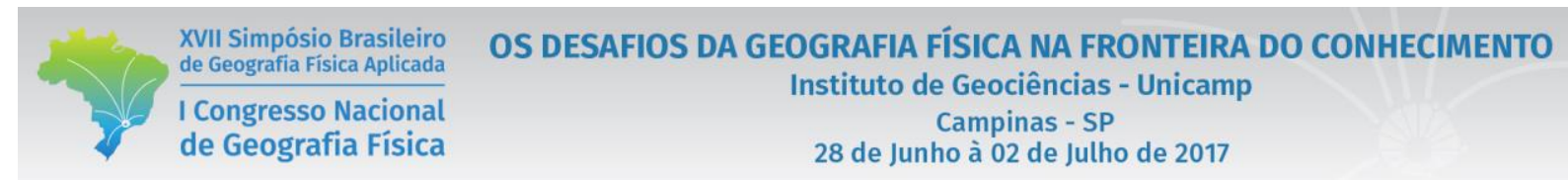

Brito e Prudente (2005), mapearam a cobertura vegetal nativa e o uso do solo no município de Uberlândia no ano de 2004 utilizando imagens do sensor High Resolution Camera (CCD) do satélite CBERS-2 e concluíram que $40,56 \%$ da área total do município eram ocupadas por pastagens.

O presente trabalho tem como objetivo mapear as áreas ocupadas com pastagens plantadas, estimar a porcentagem de Cobertura Verde e produtividade de Biomassa Verde para o município de Uberlândia, situado na mesorregião do Triângulo Mineiro e Alto Paranaíba, no estado de Minas Gerais, limitado pelas coordenadas geográficas de $18^{\circ} 30^{\prime}$ e $19^{\circ} 30^{\prime}$ de latitude sul e de $47^{\circ} 50^{\prime}$ e $48^{\circ} 50^{\prime}$ de longitude oeste (Figura 1).

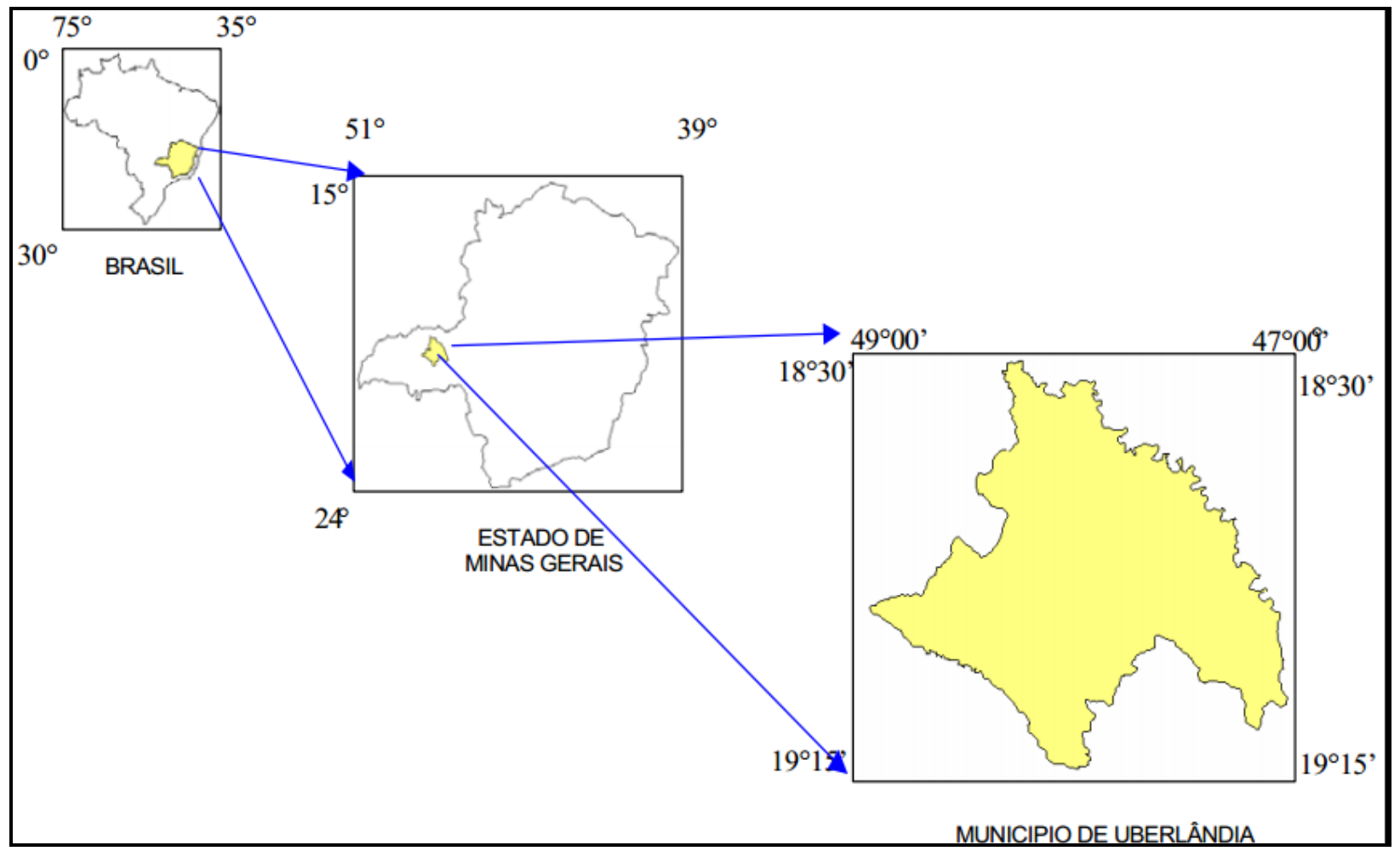

Figura 1 - Localização do Município de Uberlândia.

\section{Materiais e Métodos}

Para o mapeamento foi utilizado o software de geoprocessamento livre QGIS 2.8 e as imagens do sensor OLI do satélite Landsat-8, bandas 3, 4, e 5 da cena 221/073 obtidas nos meses de abril e outubro de 2015. Inicialmente foi elaborada a base cartográfica da área de estudo, a partir das cartas topográficas na escala 1;100.000 (IBGE,2015). 


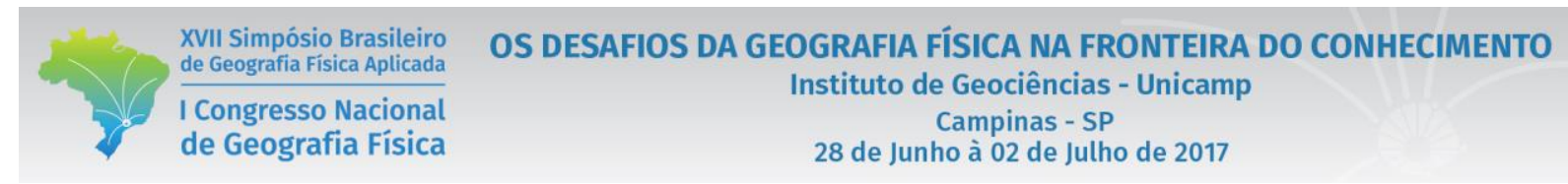

As áreas de pastagens foram delimitadas na tela do computador e assim, interpretadas pelo mesmo instrumento, utilizando a imagem OLI/Landsat-8 de 7 de Outubro de 2015 (Figuraa 2), . Comparando-se com as imagens de alta resolução do Google Earth, os polígonos foram vetorizados no software QGis.

Para a correção geométrica das imagens foi utilizada a função de correção de calibração radiométrica do software Environment for Visualizing Images, (ENVI-5), com os dados do arquivo no formato MTL que contém os parâmetros de aquisição da imagem e disponibilizado no site da United States Geological Survey (USGS) (http://earthexplorer.usgs.gov/). O mapa final das áreas de pastagens elaborado no software QGis e assim calculou a área de pastagem total em todo o território de Uberlândia/MG.

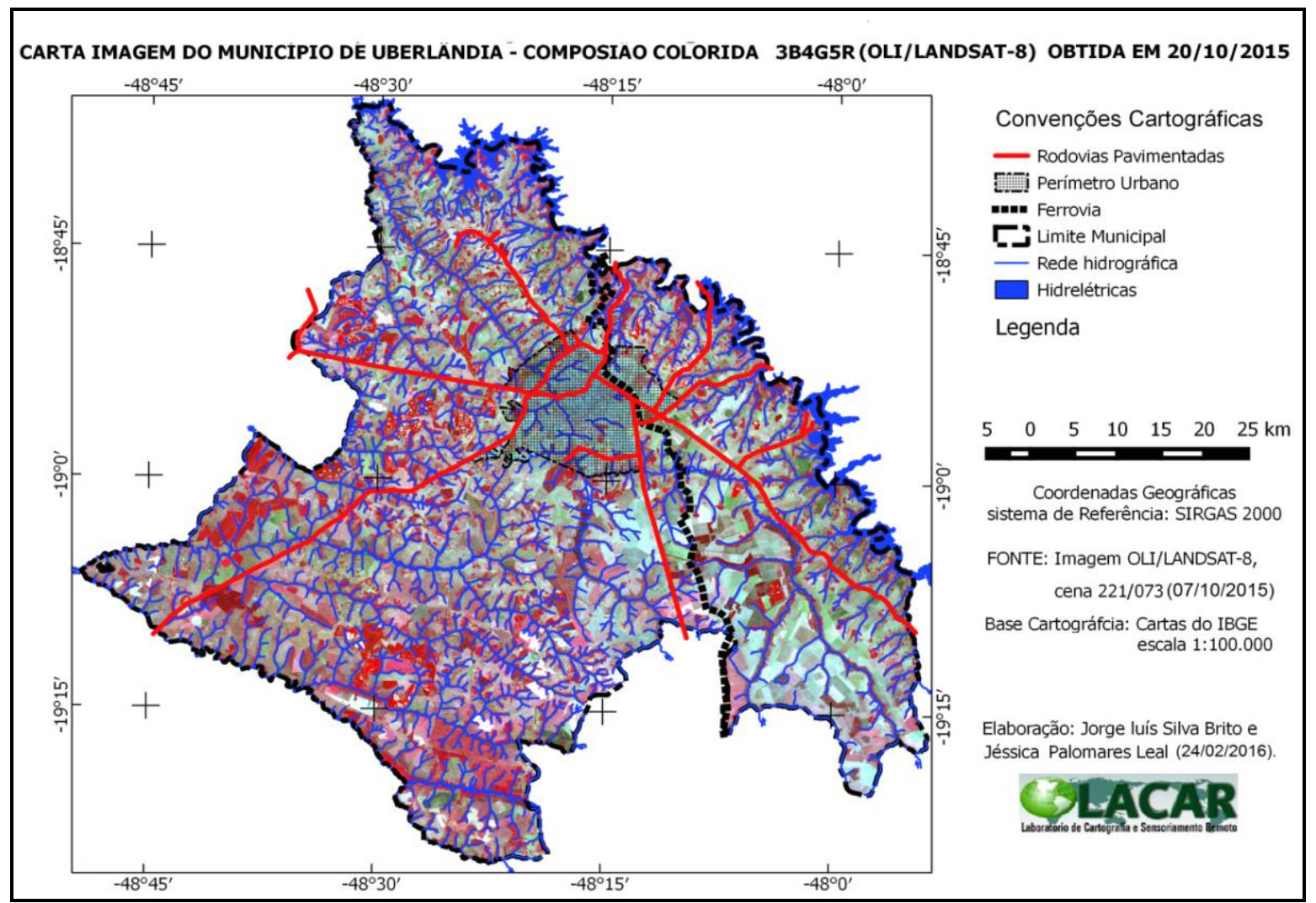

Figura 2 - Carta imagem do município de Uberlândia, composição colorida 3b4g5r, imagens OLI/Landsat-8, órbita ponto 221/073, obtida em 07 de outubro de 2015.

Para estimar o índice de Biomassa Verde (kg/Ha) e Cobertura Verde (\%) presente nas pastagens encontradas, foi necessário calcular o Índice de Vegetação Melhorado (Enhanced Vegetation Index (EVI) das mesmas. O EVI tem como função, aperfeiçoar o sinal de vegetação causando sensibilidade na detecção de regiões em que as densidades de biomassas são maiores e analogamente, diminuir a influência do sinal tanto da atmosfera quanto do solo sobre a resposta do dossel. 


\section{OS DESAFIOS DA GEOGRAFIA FÍSICA NA FRONTEIRA DO CONHECIMENTO \\ Instituto de Geociências - Unicamp \\ Campinas - SP \\ 28 de Junho à 02 de Julho de 2017}

O índice de vegetação EVI2, foi então calculado, utilizando as bandas 4 (corresponde a faixa espectral do Vermelho) e a banda 5 (correspondente a faixa espectral do infravermelho próximo) do sensor OLI/Landsat-8, utilizando a equação definida por Jiang et al (2008):

$$
E V I 2=2,5 \frac{\left(\rho_{\text {nir }}-\rho_{\text {red }}\right)}{\rho_{\text {nir }}+2,4 \rho_{\text {red }}+1}
$$

Onde $\rho_{\text {red }}$ é a reflectância na banda do vermelho (Banda 4 do sensor OLI/Landsat-8) e $\rho_{\text {nir }}$ é banda do infravermelho próximo (Banda 5 do sensor OLI/Landsat-8) .

Os valores de Biomassa Verde e da Cobertura Verde foram estimados e em função do EVI2 das pastagens, utilizando as equações determinadas por Brito (2014):

$$
\begin{aligned}
& \text { Biomassa Verde }=1895,6 \ln (\text { EVI2 })+3603,3 \quad(\mathrm{Kg} / \mathrm{Ha}) \\
& \text { Cobertura Verde }=57,426 \ln (\text { EVI2 })+114,31 \quad(\%)
\end{aligned}
$$

\section{Resultados}

A seguir são mostrados os resultados do mapeamento das áreas de pastagens e a estimativa da Biomassa Verde e Cobertura Verde, utilizando as imagens do sensor $O L I$ do satélite Landsat- 8 e as equações obtidas por Brito (2014).

O mapa da figura 1 mostra a carta imagem da composição colorida, bandas $3 \mathrm{~b} 4 \mathrm{~g} 5 \mathrm{r}$ da imagem OLI/Landsat-8 obtida em 07 de outubro de 2015 e utilizada para o mapeamento da pastagem.

A figura 3 mostra a distribuição espacial das pastagens no município que foi obtida através da interpretação visual em tela do computador com imagem OLI/Landsat-8 de 7 de Outubro de 2015. As áreas de pastagens ocuparam 1324,85 $\mathrm{km}^{2}$, correspondendo a $32,19 \%$ da área total do município de Uberlândia, que é de 4115,20 km². Comparando esses valores com os valores obtidos por Brito e Prudente (2004), verificou-se que entre o período de 2004 a 2015 houve uma redução de 8,37\% na área ocupada por pastagens no município de Uberlândia. Essa redução deve-se principalmente pela substituição das áreas ocupadas com pastagens por culturas da cana de açúcar e culturas anuais de soja e milho. 

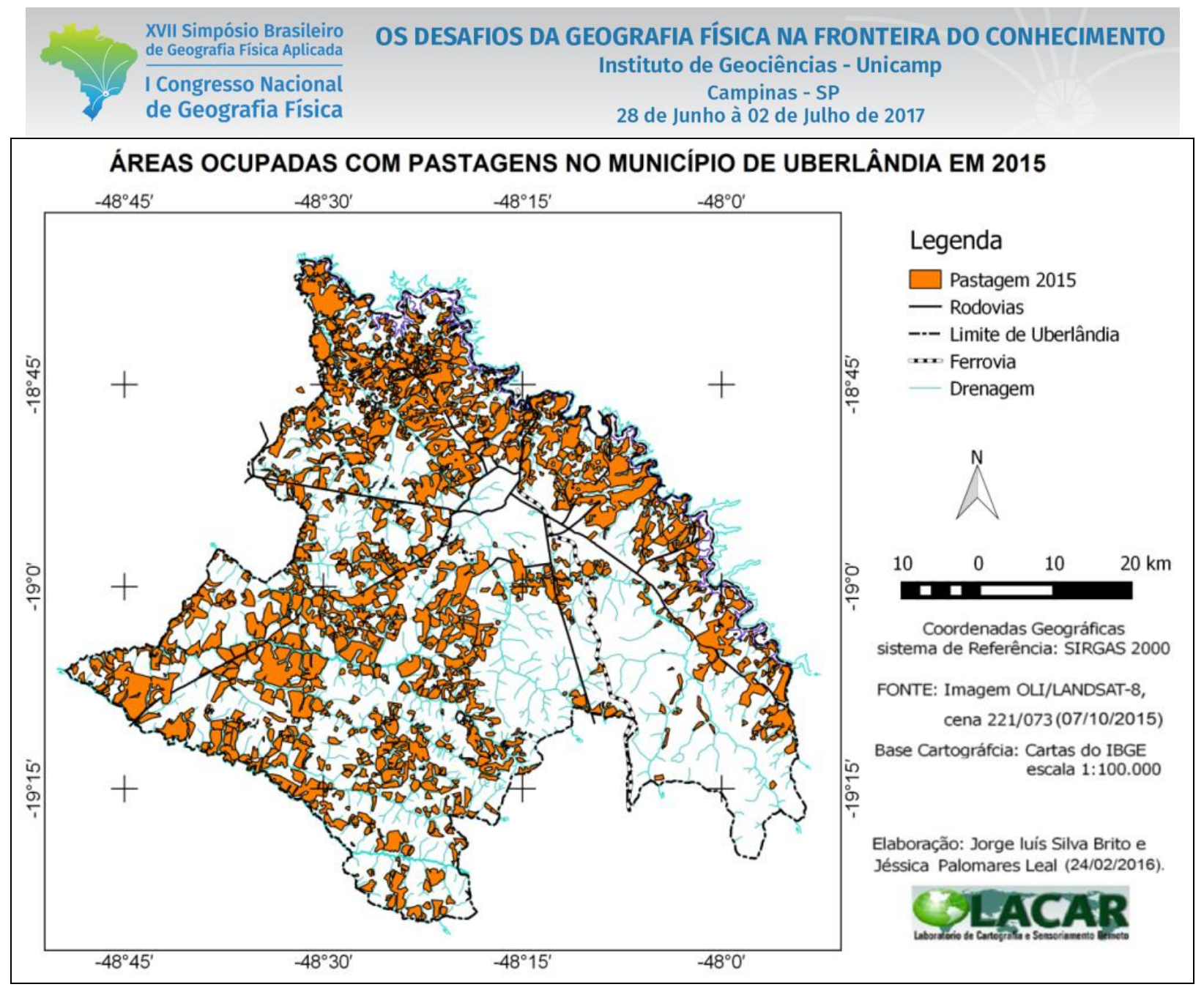

Figura 2 - Mapa das áreas ocupadas com pastagens no município de Uberlândia em 2015.

As figuras 3 e 4 mostram os valores de Biomassa Verde e porcentagem de Cobertura Verde estimados a partir do EVI2, utilizando as Equações 2 e 3 determinadas por Brito, 2014, para o município de Uberlândia. 

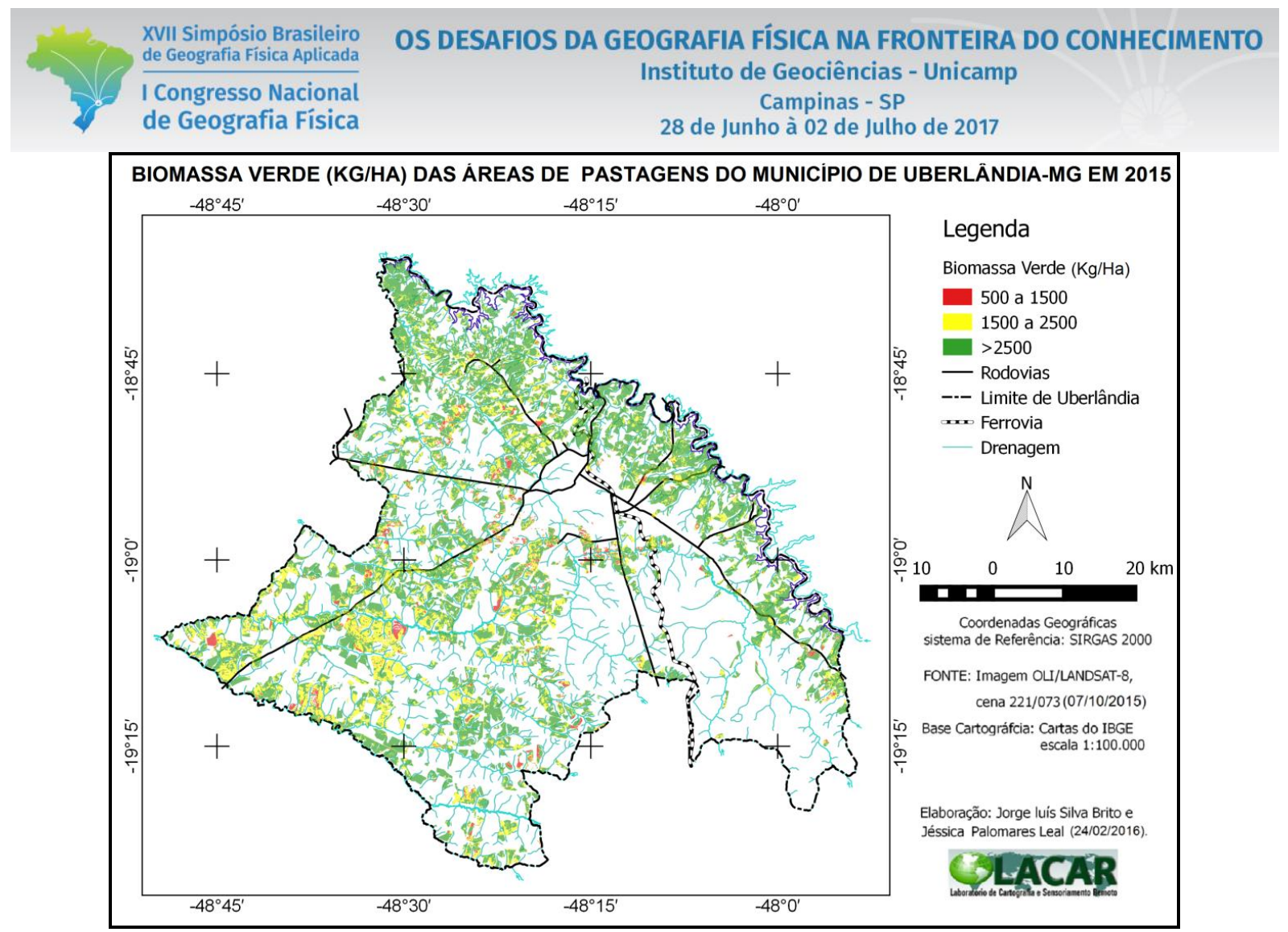

Figura 3 - Mapa de produtividade de Biomassa Verde das áreas de pastagem do município de Uberlândia em abril de 2015.

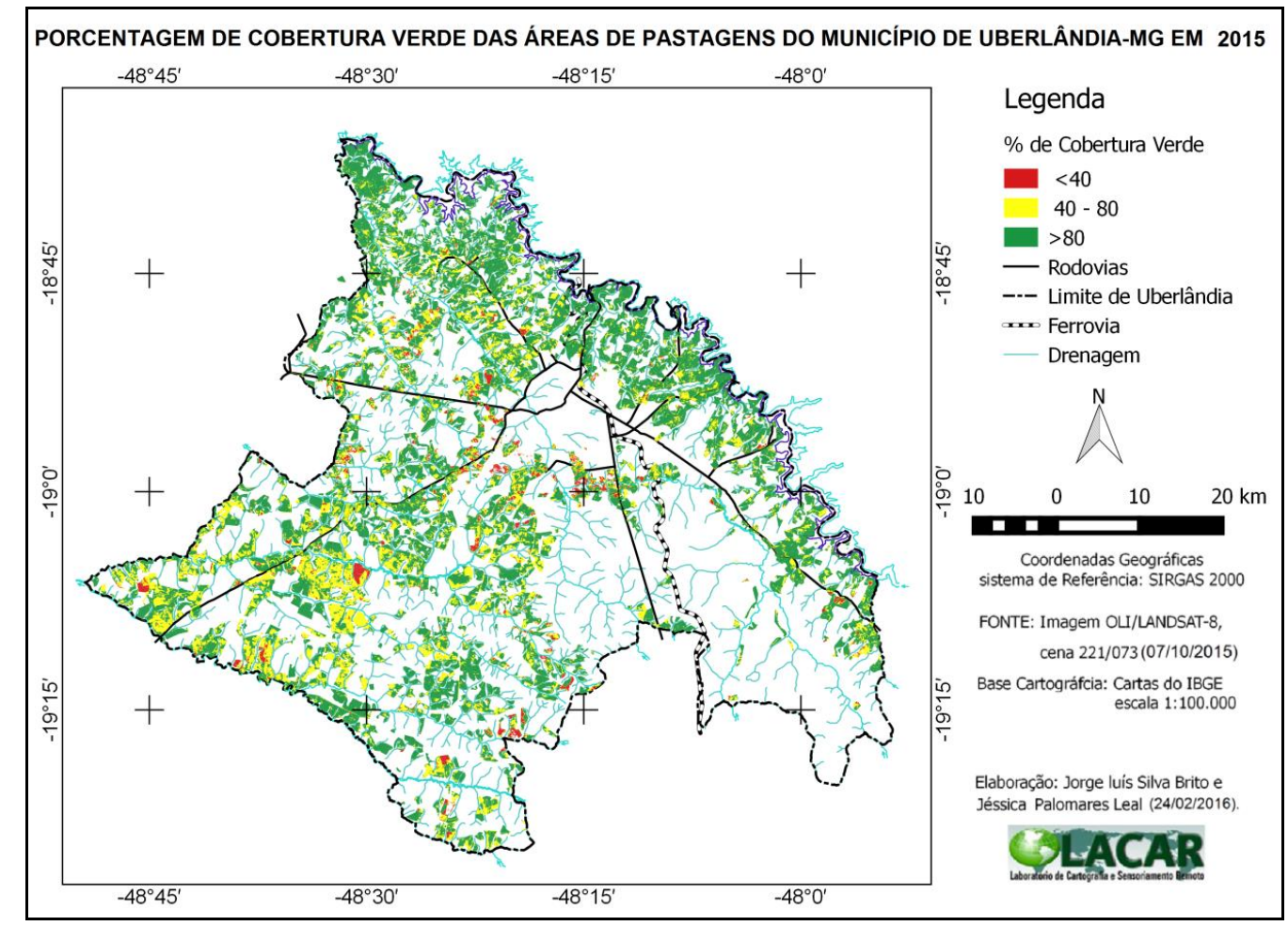

Figura 4 - Mapa de Produtividade de Biomassa Verde das áreas de pastagem do município de Uberlândia em abril de 2015. 
As áreas com valores de baixa produtividade de Biomassa Verde, entre 500 e 1500 kg/Ha/ano (Figura 3), estão concentrados na porção sudoeste do município, onde os solos são mais arenosos, enquanto que as áreas valores de alta produtividade de Biomassa Verde, maiores que $2500 \mathrm{Kg} / \mathrm{Ha}$, estão localizados na porção Norte do município, onde ocorrem solos mais argilosos.

As áreas com baixa porcentagem de cobertura vegetal, menor $40 \%$ (Figura 4), estão concentradas na porção sudoeste do município, onde os solos são mais arenosos, enquanto que as áreas porcentagem de cobertura verde, maiores $80 \%$, estão localizados na porção Norte do município, onde ocorrem solos mais argilosos.

\section{Considerações Finais}

As áreas de pastagens ocuparam 1324,85 km², correspondendo a 32,19\% da área total do município, que é de 4.115,20 $\mathrm{Km}^{2}$. Segundo Brito e prudente (2004), no ano de 2004 as áreas de pastagens ocupavam 1669,22 km² , correspondendo a 40,5 da área total do município de Uberlândia. Comparando-se esses resultados, conclui-se que entre os anos de 2004 e 2015 houve uma redução de 8,37\% na área ocupada com pastagens no município de Uberlândia. Essas áreas foram substituídas, principalmente pela cultura da cana de açúcar e por culturas anuais de soja e milho.

As áreas com valores baixa produtividade de Biomassa Verde, entre 500 e $1500 \mathrm{~kg} / \mathrm{Ha} / \mathrm{ano}$, e valores de cobertura verde inferiores a $40 \%$ estão concentrados na porção sudoeste do município, onde os solos são mais arenosos. Já as áreas valores de alta produtividade de Biomassa Verde, maiores que $2500 \mathrm{Kg} / \mathrm{há}$, valores de cobertura verde superiores a $80 \%$ estão localizados na porção Norte do município, onde ocorrem solos mais argilosos.

\section{Agradecimentos}

Agradecimentos a Fundação de amparo à pesquisa do Estado de Minas Gerais (FAPEMIG) pelo auxílio na Pesquisa através do projeto n ${ }^{\circ}$ CRA-APQ-01542-14.

\section{Bibliografia}

ANJOS, V.S.; SANO, E.E.; BEZERRA, H.S.; ROSA, R. Caracterização espectro-temporal de pastagens do Triângulo Mineiro utilizando dados MODIS EVI2 (2000-2010). Sociedade \& Natureza, v.25, n.1, p. 205-215, 2013.

BRITO, J.L.S. Métricas de correlação entre dados de campo e imagens de satélite multiescalares em áreas ocupadas com pastagens cultivadas. Relatório de Pós Doutorado, Goiania, IESA/UFG, 2014. 
BRITO, J.L.S.; PRUDENTE, T.D. Análise temporal do uso do solo e cobertura vegetal do município de Uberlândia-MG, utilizando imagens ETM+/Landsat 7. Sociedade \& Natureza, v. 17, n. 32, p. 37-46, 2005.

FERREIRA, L.G.; SANO, E. E. ;FERNANDEZ, L.; ARAÚJO, F. M. Biophysical characteristics and fire occurrence of cultivated pastures in the Brazilian savanna observed by moderate resolution satellite data. International Journal of Remote Sensing, 2012.

FRANCO, J.B.S. ROSA, R. Análise da possibilidade de identificar pastagens degradadas utilizando dados radiométricos de campo. Revista Sociedade \& Natureza, v.16, p. 37-55. 2004.

IBGE. Instituto Brasileiro de Geografia e Estatística - IBGE. Cartas Topográficas. Disponível em: <http://www.ibge.gov.br> Acesso em: Setembro 2015.

JIANG, Z.; HUETE, A. R.; DIDAN, K.; MIURA, T. Development of a two-band enhanced vegetation index without a blue band. Remote sensing of Environment, v. 112, p. 3833-3845, 2008.

MACEDO, M.C.M.; ZIMMER, A.H. Sistema pasto-lavoura e seus efeitos na produtividade agropecuária. In:Favoretto, V.; Rodrigues, L.R.A.; Reis, R.A. (eds.). SIMPÓSIO SOBRE ECOSSISTEMAS DE PASTAGENS, 2, 1993, Jaboticabal. Anais. Jaboticabal: FUNEP, UNESP, 1993. p. 216-245.

SANO, E. E.; BEZERRA, H. S. ; BARCELLO, A. O. ; ROSA, R. Metodologias para mapeamento de pastagens degradadas no Cerrado. Planaltina/DF: Embrapa Cerrados, 2002 (Boletim de Pesquisa, 70). 